Acta Poetica 27 (1)

PRIMAVERA

2006

\title{
Voz, sentido y diálogo en Bajtín
}

\section{Tatiana Bubnova}

El artículo destaca la relación que los principales conceptos bajtinianos vinculados al diálogo, tales como voz, oído, escucha, tono, tonalidad, entonación, acento, etc., mantienen con lo oral. A diferencia de otros teóricos, Bajtín no hace una separación drástica entre la cultura oral y la escrita. En cambio, vincula toda comunicación a la idea del acto ético y la responsabilidad. De ahí, la literatura resulta un acto responsable que tiene cualidad sonora. La voz tiene connotaciones personalistas y responsables.

The article emphasizes the oral quality of the main Bakhtinian concepts related to dialogue, such as voice, hearing, listener, tone, tonality, intonation, accent and others. Bakhtin, unlike other theoreticians, doesn't divide drastically the oral from the written culture. Instead, he refers the idea of all communication phenomenon to the idea of the ethical act, and, in consequence, literature results in an act with acoustic quality as the base of dialogue, and is metaphorically extended from oral to written texts. Voice has personalist and answerable connotations. 



\section{Tatiana Bubnova}

Universidad Nacional Autónoma de México

\section{Voz, sentido y diálogo en Bajtín}

Aun suena el sonido, aunque su causa haya desaparecido.

MANDELSTAM

Sólo por la voz entenderemos lo que aquí luchaba y se resistía, y llevaremos el áspero grafito por donde la voz señale.

El filósofo ruso del lenguaje Mijaíl Bajtín, a pesar de no haberse ocupado del folclore y la tradición oral sino de la literatura escrita más bien canónica, utiliza ampliamente el vocabulario relacionado con lo oral, la voz, el oído, la escucha, el tono, la tonalidad, la entonación, el acento, etc. A diferencia de otros teóricos, como Walter Ong, no maneja la oralidad como un dominio aparte opuesto a la escritura, y no hace una drástica división entre cultura oral y cultura escrita como dos ámbitos contrastantes. ${ }^{1}$ Por el contrario, el mundo pensado por

${ }^{1}$ Las diferencias entre los dos ámbitos aparecen señaladas en su texto "Problema de los géneros discursivos" (en 1982 [1979], 248-293), en que hace una oposición entre los géneros discursivos primarios (principalmente orales) y los secundarios, que pertenecen a la esfera de la comunicación discursiva escrita. Otro texto que puede consultarse sobre la diferencia entre la comunicación oral y 
él, tanto el de la voz como el de la letra, aparece unificado por la producción dinámica de los sentidos, ${ }^{2}$ generados y transmitidos por las voces personalizadas, que representan posiciones éticas e ideológicas diferenciadas en una conjunción e intercambio continuo con las demás voces. ${ }^{3}$ En el centro de su concepción del mundo se encuentra el hombre en permanente interacción con sus semejantes mediante el lenguaje entendido como acto ético, como acción, como comunicación dinámica, como energeia. ${ }^{4}$ Desde este punto de vista, la escritura no es sino la transcripción codificada de las voces capaz de transmitir los sentidos de este diálogo ontológico — puesto que según Bajtín ser es comunicarse dialógicamente- y no un medio autónomo que genere sentidos propios, muchas veces contradictorios consigo mismos y a menudo en conflicto con las supuestas "intenciones" de los sujetos que escriben, como sucede en las teorías de la deconstrucción dedicadas a la escritura. Para decirlo con Paul Zumthor, ${ }^{5}$ "el texto no es más que la oportunidad del gesto vocal" (65). En el mundo de Bajtín, la escritura no se privilegia sino justamente como un recurso capaz de traducir las voz humana en la medida en que es portadora de los sentidos de la existencia, preservando de un modo específico sus modalidades, que él caracteriza mediante metáforas relacionadas con la voz y la música: polifonía, con-

la escrita es el de V. N. Volóshinov, "La palabra en la vida y la palabra en la poesía”, en M. Bajtín 1997, 106-137.

2 "Llamo sentidos las respuestas a las preguntas. Lo que no responde ninguna pregunta, para nosotros carece de sentido" (Bajtín 1979, 350).

${ }^{3}$ El sentido de la voz en Bajtín es más de orden metafórico, porque no se trata de la emisión vocal sonora, "sino de la memoria semántico-social depositada en la palabra" (Dahlet 264).

${ }^{4}$ Cf. una concepción semejante del poder de la palabra en la Edad Media que encontramos en Paul Zumthor: "El Verbo se difunde a lo largo del mundo por el que fue creado y al que da vida. En la palabra tiene su origen el poder del jefe y de la política, del campesino y de la simiente. El artesano que moldea un objeto pronuncia las palabras que fecundan su acto... [L]a palabra proferida por la Voz crea lo que dice" (89).

${ }^{5}$ Quien lo dice, es cierto, a propósito de la cultura medieval. 
trapunto, orquestación, palabra a dos voces, coro, tono, tonalidad, entonación, acento, etc. No son categorías estilísticas en el sentido tradicional, que se presentan como rasgos distintivos de los autores individuales, sino que son concebidas como una especie de memoria semántico-social (cf. Dahlet) cuyo depositario es la forma de las palabras, y en este aspecto son ante todo portadoras de valoración social. La misma palabra enunciado, que es la unidad mínima del sentido (que puede ser contestada) en la comunicación discursiva, en su versión rusa está ligada al hablar, articular, argumentar; en una palabra, se trata de dar voz a alguien, tanto en su proceso como en su resultado: vyskazyvanie. ${ }^{6}$ El enunciado es, pues, la metáfora de la oralidad codificada por escrito, es una unidad mínima de sentido que puede ser contestada en el proceso de la comunicación dialógica.

El mundo que nos rodea, según Bajtín, está poblado de voces de otras personas, voces que son palabras en el sentido de "enunciados": "Vivo en un mundo poblado de palabras ajenas. Y toda mi vida, entonces, no es sino la orientación en el mundo de las palabras ajenas, desde asimilarlas, en el proceso de adquisición del habla, y hasta apropiarme de todos los tesoros de la cultura" (1979a, 347-348), entendiendo por ésta la comunicación discursiva de "segundo grado", o sea la escrita. Pero sin duda alguna Bajtín habla de las palabras escritas sólo en una segunda instancia, partiendo de la comunicación oral, y en la escritura resuenan, para él, de un modo virtual, pero semióticamente perceptible, las voces de las otras personas, de opiniones, de posiciones individuales y de grupos sociales. Esta

${ }^{6}$ La palabra rusa vyskazyvanie no corresponde con perfección a su equivalente castellano: enunciado, tomado en su sentido específicamente teórico del francés. En el contexto teórico, remite a la intertextualidad, idea de Kristeva ciertamente derivada de Bajtín, pero adaptada a la ideología de la écriture. La palabra rusa remite al contexto oral o virtualmente oral, y al mismo tiempo significa 'enunciado' y 'enunciación', 'proceso' y 'resultado', cancelando la dicotomía entre lengua y habla. Cf. el breve texto de Bajtín (2001). 
situación primaria vocalizada, polifónica, que es el sobreentendido básico de la concepción del mundo de nuestro pensador, ha sido comparada con la de una mente esquizoide, pero tal interpretación es sin duda el efecto del impacto de la psiquiatría y el psicoanálisis en nuestra comprensión de sí mismos: las voces de las que habla Bajtín son constructoras del sentido de nuestras enunciaciones por incitarnos a la respuesta, no necesariamente agresiones a nuestro ser. Para forjar un nuevo sentido a partir de las voces ajenas nos involucramos en un proceso de comprensión de lo que se dijo antes de nosotros, y tratamos de oír, anticipándola, la posible respuesta de nuestros interlocutores. Las palabras todas van dirigidas a alguien y son de alguien (no hay palabras neutras, que existan por su cuenta), y decir palabras propias _las que le "pertenecen" a uno- sólo es posible en respuesta a algo que se dijo antes de nosotros. Es en el proceso de la comunicación verbal, de la interacción con el otro, como uno se hace sujeto forjando su propio yo. El "yo" sólo existe en la medida en que está relacionado a un "tú": "Ser significa comunicarse", y un 'yo' es alguien a quien se le han dirigido como a un 'tú'.

Así pues, la omnipresencia de la voz es equiparable a la ubicuidad del otro en nuestra existencia, de tal modo que la construcción del yo mediante lo verbal pasa por el diálogo como forma primaria de comunicación y pensamiento y, más aun, como concepción del sujeto y su ser. Esta concepción lingüístico-discursiva corresponde a los términos de la antropología filosófica bajtiniana, su "filosofía primera", en la que se perfila el mismo ser como algo que nos habla: como "ser expresivo y hablante", que es, ciertamente, el objeto de las humanidades $(1996,8)$. Y puesto que Bajtín es ante todo un filósofo, para entender cómo funciona en su pensamiento alguna cuestión particular, por ejemplo la de la palabra sonora, conviene recurrir a su concepción general del mundo para situar adecuadamente el concepto de la voz y el sentido. El hombre y su hacer 
en una intensa interacción con otro hombre está, como he dicho, en el centro de su "primera filosofía". Percibimos nuestro mundo no sólo mediante sentidos físicos, sino también morales, que son las valoraciones generadas por mis actos que siempre se realizan en presencia y en cooperación con el otro ser humano, a través de una triple óptica en que vemos el mundo: yo-para-mí, yo-para-otro, otro-para-mí, de tal modo que el mundo resulta ser el espacio en que se desarrolla nuestra actividad, concebida siempre en una estrecha participación del otro. El espacio es donde el otro siempre se encuentra, mientras que yo tengo que entrar en el espacio. Cada quehacer, cada expresión o gesto, cada tarea son para otro; por eso el acto siempre será un encuentro con el otro, encuentro basado en una responsabilidad específica que la relación con el otro produce: mi posición en el espacio y el tiempo es única e irrepetible, por eso yo soy la única persona capaz de realizar los actos concretos que me corresponden desde mi único sitio en el mundo, actos que nadie puede llevar a cabo en mi lugar. Pero son actos "para-otro". Estos actos, realizados "para otro", buscando su mirada y su sanción, repercuten de una manera definitiva en otra persona y en el mundo. Lo que sucede entre nosotros, entre el "tú" y el "yo", es un "acontecimiento del ser", un "aconteSer", un suceso dinámico abierto que tiene carácter de interrogación y respuesta a la vez, y una proyección ontológica: el "acontecimiento del ser" es, en ruso, sobytie bytia, un "ser juntos en el ser". Cualquier acto nuestro que no sea fortuito obedece a la tensión permanente del deber ser, de obligatoriedad que emana para mí del otro; es un acto entendido como "acto ético" (postupok), que nos hace contraer responsabilidad y admitir consecuencias: "en el ser no hay coartada". Al involucrarnos en un sistema de relaciones con los otros en el cual nada se pierde, sino que tiene un efecto irremisible, sea inmediato o a largo plazo, sobre algo o alguien: ser en el mundo compromete. El acto es una respuesta a algún 
acto anterior que, en cuanto tal, posee un sentido, y al provocar una respuesta en el otro genera otro sentido nuevo: la filosofía del acto ético según Bajtín prefigura la filosofía dialógica en la cual a los parámetos descriptivos del acto se les añade otro ingrediente decisivo, constituyente de lo humano, que es la palabra, que para el ser humano siempre ha estado ahí, como el otro.

La lengua, si no lo es todo en la vida humana, está en todo, orgánicamente integrada en el acto ético bilateral, de modo que se puede hablar, entre la infinita variedad de los actos humanos, de acto acción física, acto pensamiento, acto sentimiento, acto estético o artístico, acto cognoscitivo, y del acto enunciado en sí. El lenguaje está orgánicamente integrado en todo tipo de actos. Así, el sentido de la palabra dicha se fusiona y se imbrica con la acción y adquiere el poder de una acción. Asimismo, la palabra escrita conserva este poder de ascendente sobre el mundo y contiene elementos persuasivos capaces de provocar la respuesta del otro. Y estos elementos de la palabra escrita están pensados como elementos del discurso oral traducido en letra, como rasgos estructurales que constituyen una voz escrita.

De este modo, nuestro mundo existe animado por la palabra sonora, que no es llevada por el viento, sino que posee el valor de un acto ético, la fuerza persuasiva de un enunciado acción, y en potencia las propiedades estéticas de un objeto de arte. ${ }^{7}$ Pero lo más importante es que las palabras pueden existir únicamente en forma de diálogo, lo mismo que el sujeto, el yo, sólo existe en una interacción con el otro que le da origen en el momento de dirigirle palabra por medio de un tú, para que podamos reconocer humildemente: "yo también soy".

${ }^{7}$ Un objeto estético en Bajtín no es una cosa, sino un constructo que se ubica en la frontera entre el autor y el receptor de una obra (en nuestro caso, de la palabra) y es producto de su interacción. 
Este dominio del sentido dialógico es pensado en términos vocales, de alternancia entre el sonido y su ausencia. El territorio del enunciado entendido como comunicación abarca no sólo lo dicho explícitamente, sino también la esfera del silencio significativo, de lo sobreentendido, de lo no dicho, de lo no decible o lo inefable, etc. La significación de la voz que suena alterna con la significación del callar, del silencio que es pausa en el proceso de la enunciación, del intercambio discursivo. El dominio del discurso incluye, pues, no sólo lo estrictamente vocalizado, sino también los gestos y las expresiones corporales, las pausas, las ausencias, las respuestas tácitas, los sentidos mudos. ${ }^{8}$ Más aún, el discurso no es sólo palabras o lenguaje, no sólo nuestra jerga extraoficial y no sólo el recurso de supervivencia, aunque tales funciones sean propias de un registro bajo. No sólo se trata del canto y la poesía, prosa o drama, argumento o sermón, aunque éstos sean registros "altos" del discurso. Más allá de los límites de las formas verbales es discurso también cualquier forma totalmente seria de la autoexpresión del ser humano, desde el abrazo y la caricia hasta la danza y la sinfonía (cf. Gardner 1993, 40-41).

Bajtín atrae la atención hacia el estatus de la alternancia del silencio y el sonido, de la percepción del sonido (sobre el fondo del silencio). Este silencio significativo debe entenderse como ausencia de la palabra, no como una mera ausencia del sonido no significativo, "natural". El romper el silencio mediante el sonido es una acción mecánica, el romper el callar mediante la palabra es un acto personalizado y pleno de sentido. En el silencio nada suena (o algo no suena); en la taciturnidad nadie habla (o alguien no habla). El callar sólo es posible en un mundo humano (y tiene sentido solamente para el ser humano). La se-

\footnotetext{
${ }^{8}$ Peter Burke habla del silencio significativo: "guardar silencio es en sí mismo un acto de comunicación" (155). "El silencio oportuno tiene más elocuencia que el discurso". "Si dice, ch'un tacere a tempo avanza ogni bel parlare". Pero por supuesto su observación tiene un alcance histórico sin llegar a una generalización filosófica bajtiniana.
} 
cuencia de callar — sonido pleno de sentido (palabra) — y pausa representa una determinada logosfera, una estructura unificada y continua, una totalidad abierta (inconclusa) que viene a ser el modelo de la comunicación concebida como la existencia misma. El callar forma parte del acto o es acto de enunciado mudo, por así decirlo (cf. 1979, 337-338).

La combinación del sonido con el silencio significativo que responde a algo dicho y/o significado antes da por resultado el surgimiento del sentido. Sólo aquello que responde a alguna pregunta tiene sentido. El sentido es, entonces, una respuesta a algo dicho antes y es algo que puede ser respondido. La voz es, pues, la fuente de un sentido personalizado; detrás de ella hay un sujeto persona; pero no se trata de una "metafísica de la presencia", de los sentidos preexistentes e inamovibles, ni de algo fantasmal, sino de un constante devenir del sentido permanentemente generado por el acto-respuesta, que se va modificando en el tiempo al ser retomado por otros participantes en el diálogo.

A partir de una semejante concepción del mundo de lo humano, la aparición de la metáfora de la polifonía, ${ }^{9}$ una de las más características del ideario bajtiniano, deja de ser casual. La realidad misma es polifónica debido a que

toda palabra (enunciado) concreta encuentra el objeto al que va dirigida ya hablado [...], discutido, evaluado, envuelto en una neblina que le hace sombra o, por el contrario, en la luz de las palabras ajenas ya dichas acerca de él. Se encuentra enredado y penetrado por ideas comunes, puntos de vista, evaluaciones ajenas, acentos. La palabra orientada hacia su objeto entra en este medio dialógicamente agitado y tenso de las palabras, valoraciones y acentos ajenos, se entreteje con sus complejas interrelaciones, se funde con unas, rechaza otras, se entrecruza con terceras $(1975,89-90)$.

${ }^{9}$ Bajtín empieza su exposición sobre Dostoievski (1929 y 1963) con la metáfora auditiva y vocal de la polifonía. 
El sentido, por así decirlo, suena. ${ }^{10}$ Por algo Bajtín dice que la de la polifonía es de una metáfora derivada del contexto musical, pero no del todo metafórico. Este "no del todo" es un guiño hacia esta antropología filosófica que concibe el ámbito de lo humano como un espacio poblado de sonido significativo entreverado de silencio significativo, inmerso en el acto global capaz de abarcar todas las esferas de la existencia: la ética, la estética, la pragmático-cognoscitiva. En este ámbito existimos atravesados por infinitos vectores de nuestras relaciones con los otros, que pueden concebirse en forma de las voces de la polifonía, voces acciones, opiniones, ideologías.

La polifonía en su relación con el diálogo se refiere a la orquestación de las voces en diálogo abierto, sin solución. La metáfora musical está estrechamente ligada a lo dialógico y sugiere que la música es también generadora del sentido, en la medida en que la música es también un lenguaje. La misma idea de la entonación, que Bajtín suele usar para caracterizar el acto de valoración inherente al enunciado, ha sido relacionada por los teóricos de la música, como Boris Asafiev (cf. Malcuzynski 1999), con el lenguaje musical.

El carácter de acontecimiento que tiene el acto-enunciado - es acto bilateral, de doble autoría constructora de sentidodetermina su condición dialógica y su inherente responsabilidad/responsividad: la alternante capacidad de tomar conciencia de su compromiso en el acto por medio de la capacidad de responder al acto-enunciado anterior y prever una futura res-

${ }^{10}$ Cf. también: "Por su naturaleza, la palabra es social. La palabra no es una cosa, sino el medio eternamente móvil, eternamente cambiante de la comunicación social. La palabra nunca tiende a una sola conciencia, una sola voz. La vida de la palabra consiste en pasar de boca en boca, de un contexto a otro, de un colectivo social a otro, de una generación a otra generación. Con ello la palabra no olvida su camino y no puede liberarse plenamente de aquellos contextos concretos cuya parte había formado. Cada miembro de un colectivo de hablantes encuentra la palabra no como la palabra neutral de la lengua, libre de intenciones, sin ser poblada de otras voces. No: recibe la palabra de una voz ajena y plena de voz ajena" $(1929,95)$. 
puesta. Todo sentido, repito, es una respuesta a un sentido anterior, todo autor es responsable por el sentido del enunciado que emite, todo autor comparte la autoría con el receptor de su respuesta, etc. Al actuar y al hablar somos autores de los actos responsables que involucran nuestra posición en el mundo y nuestro ser. La realidad del lenguaje como acción en la versión bajtiniana es la de pluralidad de lenguajes sociales y de discursos ideológicos que constituyen un medio dinámico de la heteroglosia (pluridiscursividad) y remite a la oralidad. Es un mundo poblado de sonido del discurso oral, con sus modulaciones, acentos y entonaciones, cada uno de los cuales es portador de los matices del sentido social y personalizado situacional. Cada voz posee su cronotopía - su arraigo espaciotemporal- que la sitúa como única, y su ideología, que la identifica como entidad social.

Voz se identifica con opinión, idea, punto de vista, ${ }^{11}$ postura ideológica. Así, en la obra de Dostoievski el héroe de una novela "no es una imagen, sino la palabra plena, la voz pura; no lo vemos pero lo oímos" $(1929,45)$. "Cada héroe llega a ser una voz-postura en un diálogo inconcluso" (1996, 367). El mundo concebido así se plasma en "visiones del mundo materializadas en las voces" (1996, 354).

Las secuencias de sentido producidas por las voces constituyen un diálogo permanente, inconcluso, que nos rodea, en que existimos sumergidos, y que la prosa artística es capaz de reproducir gracias al dialogismo inherente a la palabra, logrando un efecto polifónico.

${ }^{11} \mathrm{Al}$ mismo tiempo, la voz no es lo mismo que un punto de vista, que es generalizable y no depende de la posición espaciotemporal del sujeto como la voz. Las voces en la literatura, por ejemplo (como por lo demás fuera de ella) constantemente se contaminan por otras voces circundantes y en cierta forma están dentro de una cronotopía, esto es, en una dimensión espaciotemporal ineluctable. El lector de un texto literario lo actualiza de tal modo que las voces, acentos y entonaciones potenciales son parte de un código translingüístico paralelo al semiótico. 
Para convertirse en dialógicas, las relaciones lógicas y semántico-objetuales que la semántica encuentra en las secuencias del sentido, necesitan encarnarse: deben entrar a formar parte de otra esfera del ser, volverse palabra, es decir enunciado, y adquirir un autor, eso es, un creador del enunciado determinado cuya posición está expresando (cf. 1979b, 213). "La voz plasmada en el cuerpo" es la personalización, encarnación de un sujeto concreto de una postura social (1996, 365). La voz es, pues, también la metáfora del cuerpo, de la presencia necesaria del hombre total en el diálogo en el tiempo abierto. No obstante esta concepción está muy alejada de cualquier mística: la metáfora del cuerpo sugiere la plenitud humana. Ser autor: implica estar relacionado con voluntad creadora y con posición determinada a la que se puede reaccionar dialógicamente. "La reacción dialógica personifica cualquier enunciado al que está reaccionando" (1979b, 213). No es una "presencia" metafísica que parte de una imagen de un hombre concreto. El autor puede ser físicamente desconocido, puede ser colectivo, la obra puede ser creación de una sucesión generacional, etc. Es una voluntad individualizadora plena de proyecciones sociales. Esta responsabilidad es orgánicamente ligada al acto concreto (proviene de él), pero es al mismo tiempo ontológica: está ahí siempre, como el otro.

Ser autor: implica estar relacionado con voluntad creadora y con posición determinada a la que se puede reaccionar dialógicamente. "La reacción dialógica personifica cualquier enunciado al que está reaccionando" (1979b, 213). No es una "presencia" metafísica que parte de una imagen de un hombre concreto. $\mathrm{El}$ autor puede ser físicamente desconocido, puede ser colectivo, la obra puede ser creación de una sucesión generacional, etc. Es una voluntad individualizadora plena de proyecciones sociales. Esta responsabilidad es orgánicamente ligada al acto concreto (proviene de él), pero es al mismo tiempo ontológica: está ahí siempre, como el otro. 
Las metáforas vocales de tono, entonación, tonalidad, acento, etc., materializan esta presencia, al remitir potencialmente a la corporalidad. Uno de los rasgos menos comprendidos de Bajtín es esta simultaneidad de los niveles y esferas del ser normalmente separadas en la práctica y la cognición, simultaneidad que remite a la totalidad ético-estética y pragmáticocognoscitiva del ser humano.

Así pues, la idea misma del pensamiento dialógico es inherente a la cultura oral. El diálogo es la condición primera del lenguaje. El pensamiento oral, según W. Ong, tiende al diálogo espontáneamente (Ong, 40; el interlocutor es un instrumento mnemotécnico y analítico para un hablante que no dispone del recurso de la escritura): "La condición oral básica del lenguaje es permanente" (Ong, 17).

En este diálogo primordial el ser humano participa con todas sus facultades físicas y morales que se proyectan tanto hacia la realidad de un mundo concreto cotidiano como hacia la esfera ontológica: del cuerpo a la palabra se da una intensa interacción entre el yo y el otro, al que concebimos como un tercero en la trascendencia y como el prójimo en la vida real.

Bajtín plantea como un problema no sólo para los estudios literarios, sino también para la lingüística, el de la reproducción de la voz o la palabra ajena, es decir, la representación de la palabra por la palabra, de la palabra ajena por la propia. En una palabra suena la voz propia y la voz de quien dijo esta palabra antes. El bivocalismo, palabra a dos voces, es de hecho uno de los recursos principales de la ironía, poderoso instrumento de la comunicación oral y escrita. En la palabra a dos voces hay dos puntos de vista, dos opiniones, dos intenciones que entran en conflicto. La palabra bivocal es la reacción a la palabra ajena, a la palabra de otra persona. El acento, en particular un acento ajeno, la entonación que reproduce la valoración social, es lo que determina la reproducción de la palabra del otro. "La palabra bivocal de la prosa es ambigua", dice 
Bajtín $(1975,140)$ desde varios puntos de vista, y en primer lugar porque el proceso de la comprensión de la palabra ajena reproducida conlleva siempre un desplazamiento del sentido al actualizarla. Lo que reproducidmos como opinión de alguien nunca es ciento por ciento idéntico al original.

Cuando Galdós dice: "Pensará usted que es una tarea fácil hinchar a un perro", a propósito del arte de doblar mantones de Manila, en su voz se oye un eco, muy pensadamente introducido, de Cervantes. A través de Galdós se oye Cervantes. Pero al mismo tiempo es un Cervantes oído y reproducido por Galdós, en una refracción peculiar. Cuando cuenta la historia del casamiento de Jacinta, en la voz del narrador se percibe la voz "del vecino" junto con la del narrador mismo, en una complacida interacción, pero con una distancia perceptible entre una y otra voz. De ahí que la crítica (Michael Holquist, para el caso) al hablar de la palabra bivocal evocó el efecto de ventrilocución como otra metáfora vocal que describe esta relación entre las voces pertenecientes a los sujetos diferentes. En realidad, no es una metáfora muy afortunada, porque el ventrílocuo sólo imita un verdadero diálogo entre su marioneta y él mismo. ${ }^{12}$ En la palabra a dos voces entran en colisión dos voces, dos puntos de vista, dos opiniones, y el ángulo de su mutua refracción puede oscilar, en una infinita gradación, desde la posibilidad de estar de acuerdo hasta una franca subversión, rechazo solapado y escándalo mitigado por la escritura, pero que se hace oír desde las voces sociales que integran el material primario con que un autor trabaja. La gama entre el acuerdo complaciente y el rechazo abierto puede ejemplificarse entre un Galdós que ve con cierta simpatía la familia de Ja-

12 "Let's be precise: the dialogue — so called 'dialogue' — between a ventriloquist and his puppet is nothing else than a (false) psychotic entertainment; the puppet does not have access nor the right to direct speech, and it never will be anything more that the object of the ventriloquist's word-discourse immediately substituted for itself, precisely because it is mute, because it doesn't have a voice of its own, and never will" (Malcuzynski 119). 
cinta y la voz de un Quevedo que trata de destruir a su buscón don Pablos desde el mismo corazón de su discurso. ${ }^{13}$

En el mundo de Bajtín, la palabra siempre está dirigida a alguien, dialógicamente orientada hacia el exterior, hacia el otro. La palabra que quiere ser oída y entendida, y sobre todo contestada. Como el bien de un libro consiste en ser leído (Eco), así el bien de una palabra es ser oída y contestada. En algún momento de su obra, Bajtín habla de la palabra sin respuesta, comparando la inaudibilidad con un infierno.

En resumen, la palabra oral es origen y fin del diálogo existencial que Bajtín trata de explicar mediante su exégesis literaria y teoría translinguística —una lingüística que va más allá del análisis de los elementos formales de la lengua, hacia las relaciones dialógicas que es el sentido mismo de la comunicación.

Todo miembro de la colectividad hablante se enfrenta a la palabra no en tanto que palabra natural de la lengua, libre de aspiraciones y valoraciones ajenas, despoblada de voces ajenas, sino que la recibe por medio de la voz del otro y saturada de esa voz. La palabra llega al contexto del hablante a partir de otro contexto, colmada de sentidos ajenos; su propio pensamiento la encuentra ya poblada $(1979 b, 295)$.

Bajtín propone pensar en la naturaleza dialógica de la misma vida humana: la vida es un diálogo inconcluso; el hombre participa en este diálogo tanto mediante la palabra como mediante todo su cuerpo (ojos, labios, etc.). El hombre como totalidad participa en este diálogo, pero el hombre es completamente expresivo hacia el exterior, y expresa con todo su posición en el diálogo - y en relación con el último sentido, y en relación con

13 Para la interpretación sociocrítica del Buscón, véase Cros 1980, donde el autor muestra la intención crítica y subversiva de Quevedo aristócrta queriendo desenmascarar las intenciones de ascenso social de la burguesía a través del discurso autosubversivo - la palabra bivocal — de don Pablos. 
el otro, en toda expresión hacia fuera está la actitud hacia el otro, lo interno se encuentra con lo "otro" (1996, 362).

La palabra es acto ético, acción sobre el mundo y el otro, nos hace contraer una responsabilidad concreta y ontológica a la vez para con el mundo y el otro, y es nuestra manera de ser y existir en este mundo y en la trascendencia.

\section{Bibliografía}

Bastín, Mijaíl M., Problemas literarios y estéticos [en ruso], Moscú, Judozhestvenaia Literatura, 1975.

-, Estética de la creación verbal [en ruso], Moscú, Iskusstvo, 1979a. Hay versión en español: trad. Tatiana Bubnova, México, Siglo XXI, 1982.

—, Problemas de la obra de Dostoievski [1929; en ruso], Moscú, Alkonost, 1994.

—, Problemas de la poética de Dostoievski [en ruso], Moscú, Sovetskaia Rossia, 1963; 4a ed., 1979b.

—, Obras [en ruso], vol. 5, Moscú, Ed. Russkie Slovari, 1996.

-, Hacia una filosofía del acto ético y otros escritos, Barcelona, Anthropos, 1997.

—, "Iazykirech"” [lengua y discurso], en Dialog. Carnoval. Jronotop, 1 (2001).

BuRKE, Peter, Hablar y callar. Funciones sociales del lenguaje a través de la historia [1993], trad. Alberto L. Bixio, Barcelona, Gedisa, 2001.

Cros, C., Ideología y genética textual. El caso del Buscón, Madrid, Cupsa, 1980.

DAHLET, Véronique, "A entonação no dialogismo bakhtiniano", en Beth Brait (org.), Bakhtin, dialogismo e construção do sentido, Campinas, Editora da Unicamp, 1997.

GARDNER, Clinton, Entre Oriente y Occidente [en ruso], Moscú, Naulea, 1993.

MaLcuzynski, M.-Pierrette, "Musical Theory and Mikhail Bakhtin: Towards a Dialectics of Listening", Dialog. Kanranal. Xronotop, 1 (26), 1999, 94-132. 
ONG, Walter, Oralidad y escritura: tecnologías de la palabra [1982], trad. Angelika Sherp, México, FCE, 1987.

Voloshinov, Valentín N., "La palabra en la vida y la palabra en la poesía" [en ruso], en Bajtín bajo máscara [en ruso], 5/1, Moscú, Labirint, pp. 60-87.

Zumthor, Paul, La letra y la voz de la literatura medieval, trad. Julián Presa, Madrid, Cátedra, 1989.

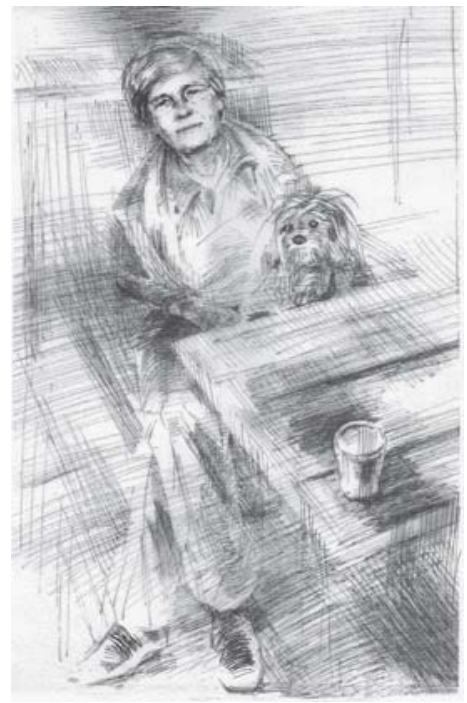

